\title{
Molecular Characterization of Sewage Bacteriophage and Their Efficiency in Treatment of Antibiotic Resistant Bacteria
}

\author{
Khalid Ibrahim Mahmood ${ }^{1}$, Ahmed Mohammed Turki ${ }^{2}$ \\ ${ }^{1}$ Scholar Researcher, Ministry of Health, Anbar Health Office, Anbar, Iraq, \\ ${ }^{2}$ Scholar Researcher, Biology Department, College of Science, University of Anbar, Iraq
}

\begin{abstract}
Background: The increasing prevalence of multi-drug resistant of bacteria strains, has become a global problem and therefore alternative method to antibiotics must be found. Bacteriophages are considered an alternative agent to control infection and contamination of the bacteria. Method: We used RAPD-PCR technique in present study, and used restriction endonuclease conformed presence unknown DNA fragments. Results: In this study, we described the isolation and character development of lytic bacteriophages capable of infecting bacteria specifically. Lytic bacteriophages, specific to Escherichia coli, Klebsiella pneumonia, Salmonella typhi, clinical strains, was first isolated from sewage. We have analyzed the DNA (RAPD)PCR technique to produce unique and reproducible band from 21 different bacteriophages infecting E.coli, $K$. pneumonia, S. typhi . Used restriction endonuclease conformed presence unknown DNA fragments. Conclusion: Phages was capable of eliciting efficient lysis of studied bacteria, revealing its potential as a non-toxic sanitizer for controlling bacterial infection and contamination in both hospital and other public environments.
\end{abstract}

Keywords: Bacteriophages, phage therapy, RAPD-PCR, Restriction endonuclease.

\section{Introduction}

The discovery of antibiotics has revolutionized the treatment of infectious diseases, and because of their overuse, resistance to antibiotics has increased and has become a global problem that must be paid attention to, and to continue to follow the side effects of antibiotics, as at least (2) million people are infected with bacteria that are resistant to some antibiotics every year in The United States alone, and at least 23,000 patients die every year from infection ${ }^{[1]}$. The danger of these antibiotics do not distinguish or differentiate between beneficial bacteria and bacteria harmful to human. the misuse of these antibiotic enables bacteria to strengthen their resistance against these antibiotic, and they become

\footnotetext{
Corresponding Author:

Khalid Ibrahim Mahmood

Scholar Researcher, Ministry of Health, Anbar Health

Office, Anbar, Iraq

e-mail: khalidibrahim361@gmail.com
}

stronger and more resistant to them ${ }^{[2]}$. Therefore, the scientists tended to phage therapy. Bacteriophages are viruses found naturally in the environment and have been studied to treat bacterial infections nearly 100 years ago. These phages invade and kill target bacteria by decomposition and do not attack mammalian cells. Phages are specialized for different bacteria. They bind to receptors on the bacterial cell walls to inject the phage DNA into the cell and eventually the cell lysis this in lytic phages ${ }^{[3]}$. During the lifecycle of the lysogenic bacteriophages, the DNA phage integrate into their host genome and evolve to coexist with bacteria. RAPD-PCR uses a randomized, purified DNA technique for extracted and purified DNA to help describe bacteriophages. RAPD-PCR is also used to assess the genetic diversity of phages ${ }^{[4]}$.

The RAPD reaction is a PCR technique that works to duplicate DNA segments that are unknown and random, using one short primer (8-12 nucleotides), and does not require any prior knowledge of the genome sequence. It also uses very low amounts of DNA, moreover, it is very sensitive, allowing the discovery of a variety of DNA 
as well as mutations. This technique is widely applied in various fields of research (medicine, forensic science, genetically modified organisms, genetic diversity, taxonomy). In addition, the RAPD technique was also applied to detect genetic instability in tumors and DNA changes caused by toxic compounds in animals, bacteria, and plants ${ }^{[5]}$.

The aim of study: Isolation of bacteriophages and study of their genetic content.

\section{Materials and Method}

Microbiological culture media and chemicals. The main microbiological culture media we used in this research were BHA (Oxoid,UK), BHI (Oxoid,UK), EMB agar (Oxoid, UK) MacConkey's agar (Oxoid,UK) and Blood agar (Oxoid,UK). The SM buffer [(Tris-HCL, $10 \mathrm{Mm} \& \mathrm{pH}=7.6 ; \mathrm{MgSO} 47 \mathrm{H} 2 \mathrm{O}, 10 \mathrm{Mm} ; \mathrm{NaCl}, 100$ $\mathrm{Mm}$ and gelatin solution $2 \%(\mathrm{w} / \mathrm{v}), 5 \mathrm{~mL}$; distilled water, up to $1000 \mathrm{~mL}$ ] (Merck, Germany). The chemicals we used were Methyl red, SIM, Urea agar, TSI and Simmon's citrate agar that provided from (Syrbio/Syria(.

Sample Collection: Collected samples from various sources including wounds, burns, urine, stool, spinal fluid and blood, were collected under aseptic conditions from Al- Anbar hospitals during the period (September to December 2019). The bacterial samples were carried immediately to the laboratory complex, Microbiology Branch, College of Science, Anbar University, Anbar, Iraq at $4 \circ \mathrm{C}$.

Isolation of bacterial species and their characterization

Isolated bacterial strains and exanimated by the compact vitek2 automated method according ${ }^{[6]}$.

Antibiotic Sensitivity Test: Bacteria strains was subjected to antibiotic resistance evaluation against a set of antibiotic discs including: Tetracycline(TE; $10 \mu \mathrm{g})$, imipenem (IPM;10 $\mu \mathrm{g}$ ), Meropenem (MEM;10 $\mu \mathrm{g}$ ), Ciprofloxacin (CiP;10 $\mu \mathrm{g})$, Ceftriaxone(CRO;10 $\mu \mathrm{g})$,

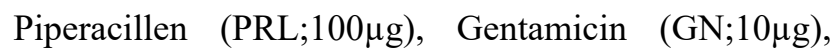
Chloramphenicol $(\mathrm{C} ; 10 \mu \mathrm{g})$, Trimethoprim $(\mathrm{T} ; 12.5 \mu \mathrm{g})$, and Nitrofurantion(F;100 $\mu \mathrm{g})$ all from(Bio analyses/ Turkey). Antimicrobial sensitivity testing was performed for strains of K. pneumoniae, E.coli and $S$. typhi using the disk diffusion method in accordance with National Committee for Clinical Standards guidelines (Clinical and Laboratory Standards Institute, 2019). The antibiotics chosen are usually used for the treatment the multi-drug resistance of bacteria.

Enrichment and isolation of bacteriophages: To isolate bacteriophages, public wastewater of Al-Anbar, Iraq was used as a possible resource.A total of $10 \mathrm{~mL}$ of wastewater for $20 \mathrm{~min}$ at $3000 \mathrm{~g}$ was centrifuged, and the supernatant was filtered using a $0.45 \mu \mathrm{L}$ syringe filter. For the enrichment of bacteriophages, $100 \mu \mathrm{L}$ overnight bacterial culture and $10 \mathrm{~mL}$ wastewater filtrates were applied to $40 \mathrm{~mL}$ of BHI flask and then incubated for 24 $\mathrm{h}$ at $37 \mathrm{C}$ at $120 \mathrm{rpm}$ shaking pace. In the same conditions, $10 \mathrm{~mL}$ of BHI broth flask was centrifuged and filtered after $24 \mathrm{~h}$. Then for the next stage the supernatant was stored at $4 \circ \mathrm{C}$. In order to confirm the presence of phages, $10 \mu \mathrm{L}$ of phage filtrate was dropped on BHA 's bacterial lawns and then incubated for 24 hours at $37{ }^{\circ} \mathrm{C} .{ }^{[7]}$.

Plaques purification and bacteriophage tittering: Double-layer agar method was used to purify the isolated phages and determine the phage titer. Briefly, phage filtrate was diluted to $10^{-12}$ using SM buffer then mixed $100 \mu \mathrm{L}$ of each dilution and $100 \mu \mathrm{L}$ of overnight bacterial culture and added to $5 \mathrm{~mL}$ of $45 \mathrm{bhc}$ molten BHA top agar $(0.5 \%$ agar $)$. Then the mixture vortexed and quickly overlaid with $1.5 \%$ agar on BHA media plates. The plates were incubated for $24 \mathrm{~h}$ at $37^{\circ} \mathrm{C}$ and the plaques of bacteriophage were enumerated on each plate. This method was executed in triplicates ${ }^{[8]}$.

Phage DNA isolation: Phage DNA was extracted as described previously from $100 \mathrm{~mL}$ of purified phage stocks previously dialyzed against SM buffer ${ }^{[9]}$.

Genomic fingerprinting by RAPD analysis: Random amplification of polymorphic DNA was carried out according to a modification of the method described previously (Johansson et al., 1995). Primers OPL5(50-ACGCAGGCAC-30) and RAPD5 (50-AACGCGCAAC-30) were assayed at concentration ( $8 \mathrm{mM})$. PCR reactions were performed using PureTaq TM Ready To-Go TM PCR Beads (GE Healthcare, Munich, Germany) adding 10ng of purified phage DNA. Reactions were supplemented with $3 \mathrm{mM}$ magnesium oxalacetate and/or 5\% v/v dimethyl sulfoxide (DMSO). PCR was performed in a thermocycler (BioRad, Hercules) under the following thermal cycling conditions: one cycles at $941 \mathrm{C}$ for $180 \mathrm{~s} ; 40$ cycles at $941 \mathrm{C}$ for $30 \mathrm{~s}, 351 \mathrm{C}$ for $45 \mathrm{~s}$ and $721 \mathrm{C}$ for $30 \mathrm{~s}$ (the extension step was increased by $1 \mathrm{~s}$ for every new cycle); and a final step of $5 \mathrm{~min}$ at $721 \mathrm{C}$. 


\section{Results}

The identity of bacteria strains was confirmed to be E.coli,S.typhi and K.pneumoniae by VITEK2 compact system . The antibiotic sensitivity of E.coli, S.typhi and K.pneumoniae isolate was tested using the disc diffusion method and the results showed that all bacteria isolate was sensitive to Meropenem, imipenem but resistant to Ciprofloxacin, Ceftriaxone, and Nitrofurantion .
In Fig.1,2 showed 50 water samples were collected from different sources and 21 isolates of Bacteriophages specific for 9 S.typhi, 7 K.pneumoniae and 5 E.coli bacteria were isolated by spotted method on solid media and double layer agar method. And the liquid media method.

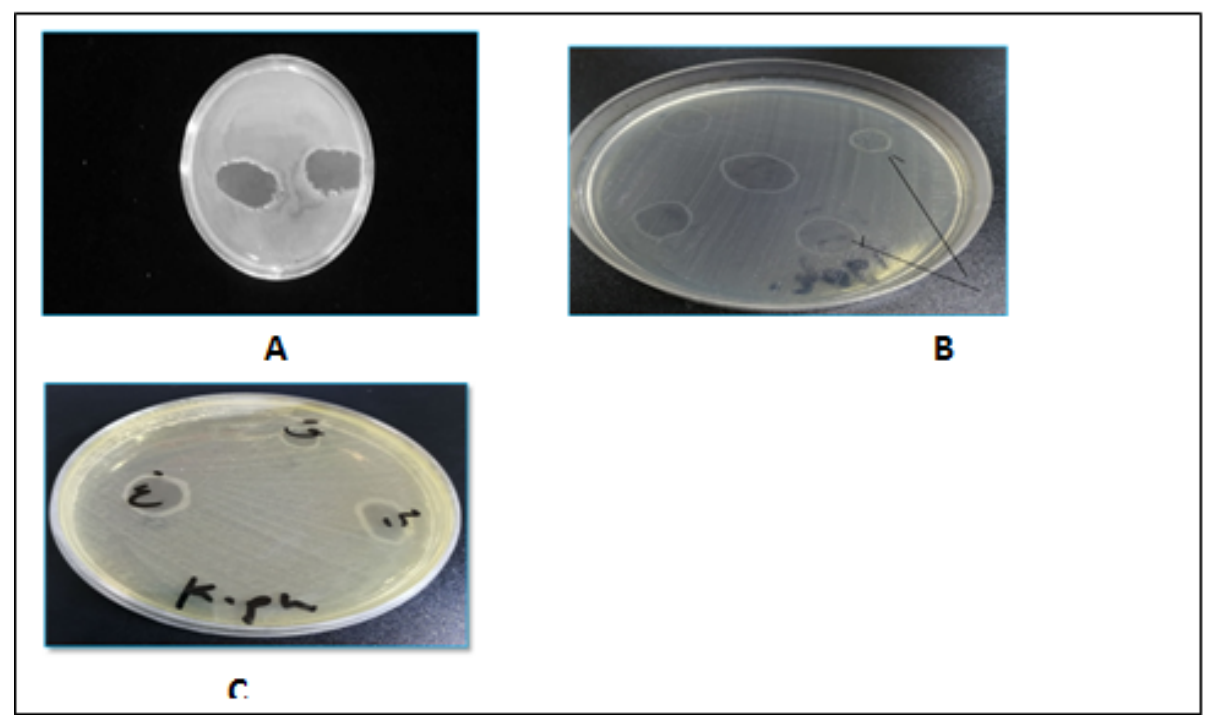

Figure 1. Plaque formation of (A) E.coli, (B) S.typhi, (C) K.pneumonia phages after $24 \mathrm{~h}$ incubation at $37^{\circ} \mathrm{C}$ on BHA

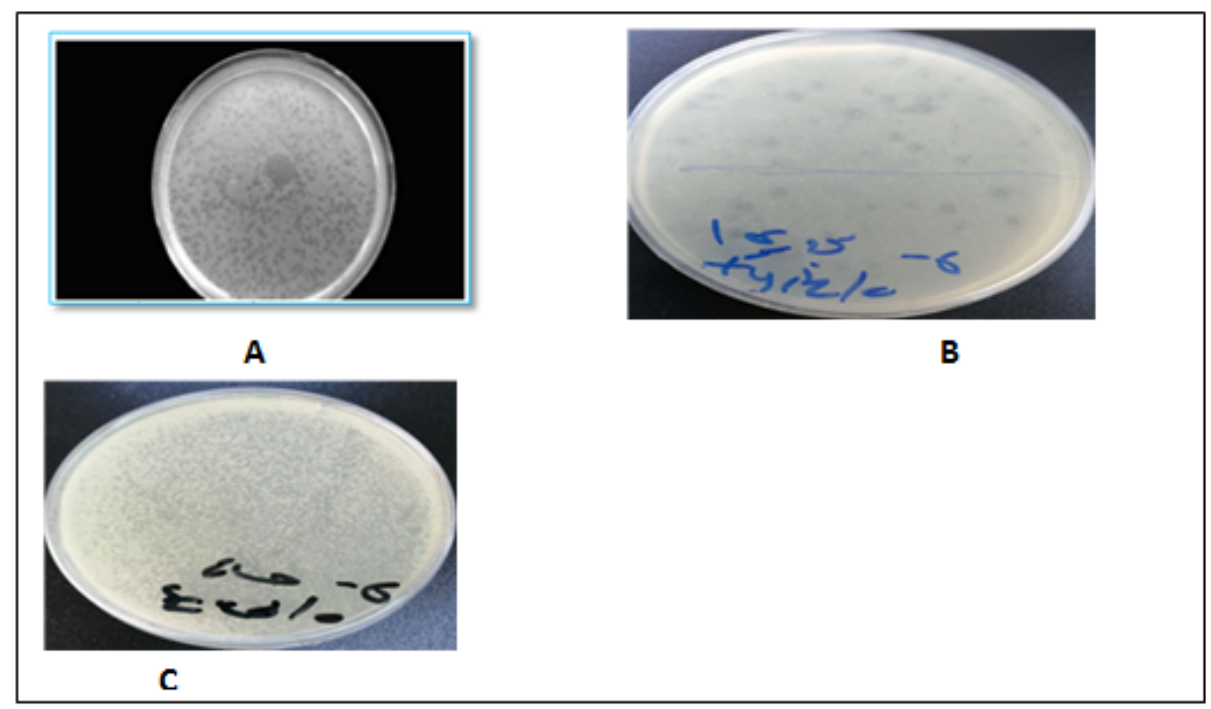

Figure 2. The total titer of (A) K.pneumonia, (B) S.typhi, (C) E.coli specific phages after 24h incubation at $37 \circ \mathrm{C}$ on BHA.

Extraction genomic DNA: DNA was extracted for all selected bacteriophages with 21 phages, which were isolated from sewage from various sources. The extraction results highlights the presence of DNA bands for all studied phages. The integrity of the extracted DNA was confirmed after gel electrophoresis $1.5 \%$. Fig. 3. 


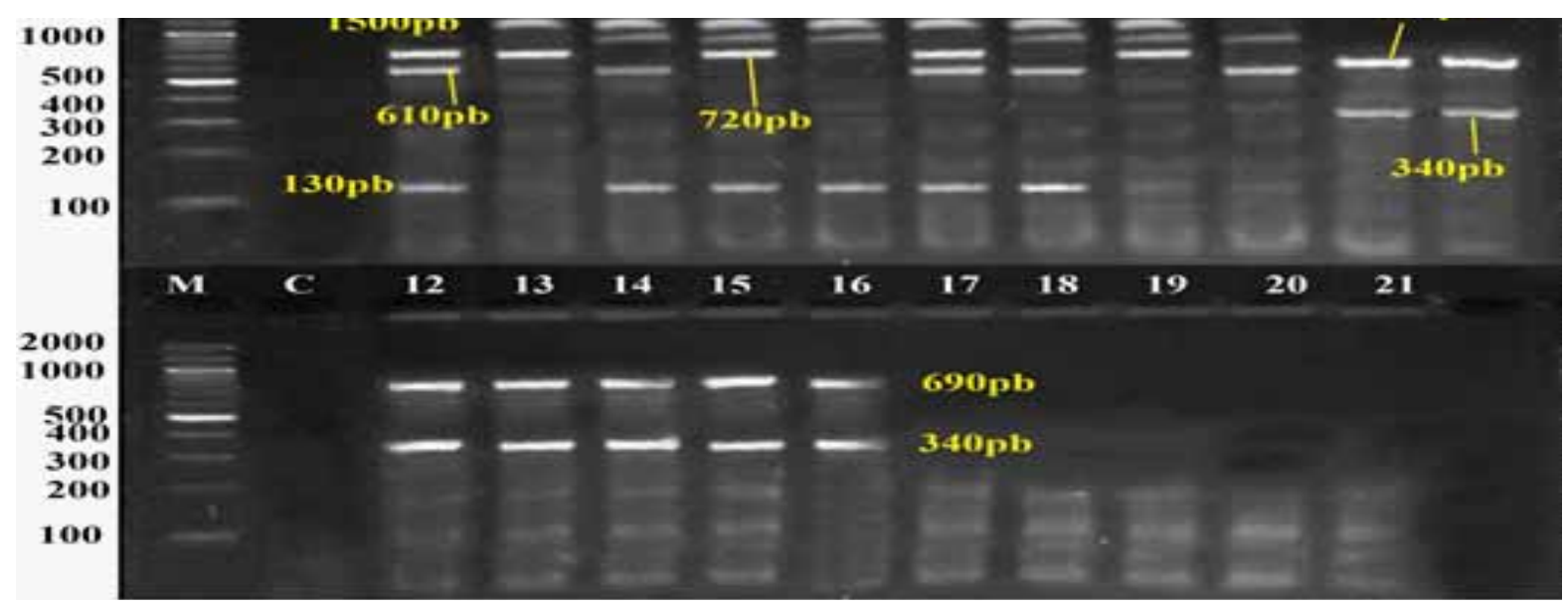

Figure 3. 21 Bands of genomic DNA and (M): DNA ladder (100 bp), agarose 1.5\%, at 70 volt for $1 \mathrm{hr}$.

Random amplification of polymorphic DNA (RAPD-PCR) technique: Fig. 4 shows RAPD-PCR random amplification technique was performed using two primers OPL5, RAPD5 for all phages. This technique showed obvious difference in the number of DNA bands and a marked variation in their molecular weights according to the primer used. In Fig.4a, $S$. typhi phages (1-9) and K. pneumonia phages (10-16) showed positive results with OPL5 primer, while E.coli phages (17-21) showed negative results. But when using RAPD5 primer showed positive results of all the phages, Fig. $4 \mathrm{~b}$.

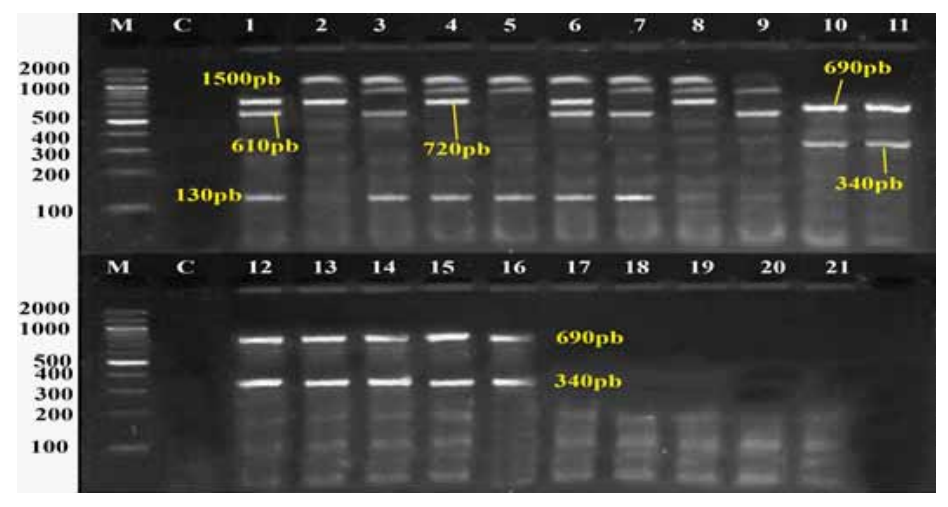

A

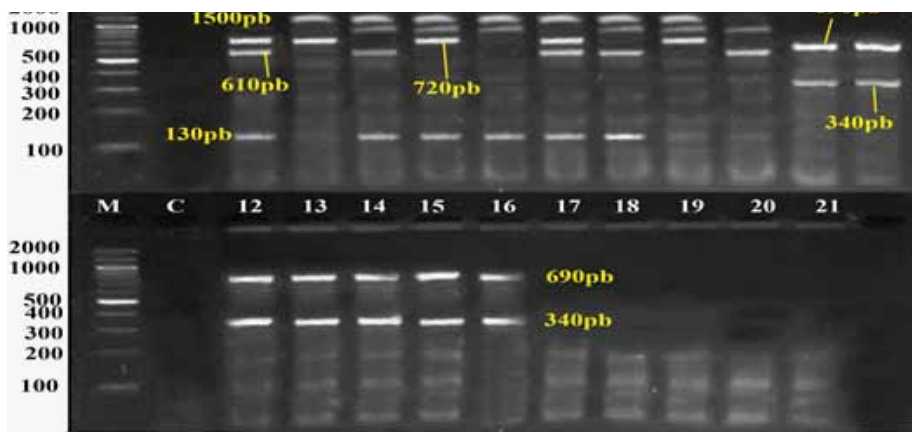

B

Figure 4. RAPD PCR products, Gel electrophoresis at 70 volt and $1 \mathrm{~h}$ on $1.5 \%$ agarose gel showing [A] using OPL5 primer lanes positive of $S$. typhi phages(1-9), lanes positive K.pneumonia phages (10-16), negative lanes of $E$.coli phages(17-21). [B] using RAPD5 primer, lanes positive of $S$. typhi phages (1-9), lanes positive K.pneumonia phages (10-16), positive lanes of E.coli phages(17-21). Lane M: DNA ladder (100bp), C: negative control. 
Restriction endonuclease enzymes: Four Restriction endonuclease enzymes (NdeI, SspI, Swa I, TaqI) were performed for all phages. The enzymes (Swa I, TaqI) did not produce positive result, while the enzymes (NdeI, SspI,) digested the DNA at more than one site and showed different bands and different weights as positive results. Fig5a, showed S.typhi phages(1-9)

similar due to similar DNA bands and also similar all E.coli phages(17-21), while showed K.pneumonia phages (10-16) negative results with using NdeI enzyme. As shown Fig4b S.typhi phages(1-9) and E.coli phages(17-21) positive results, and negative results of K.pneumonia phages (10-16) after using SspI enzyme.

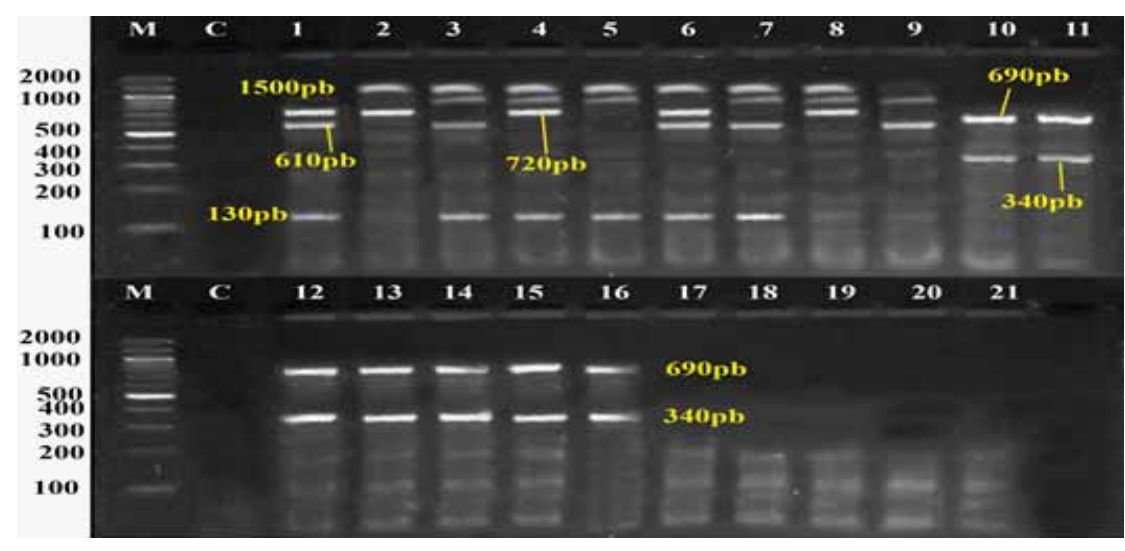

A

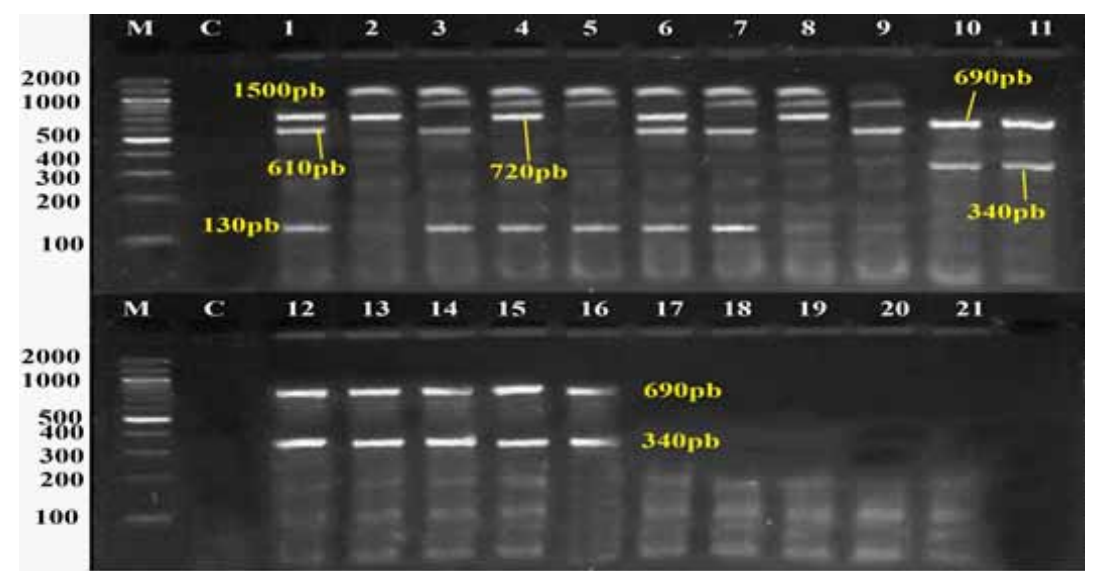

B

Figure 5. Restriction endonuclease products, Gel electrophoresis at 70 volt and $1 \mathrm{~h}$ on $1 \%$ agarose gel showing [A] using NdeI enzyme lanes positive of S.typhi phages(1-9), lanes negative K.pneumonia phages (1016), positive lanes of $E$.coli phages(17-21). [B] using SspI enzyme, lanes positive of $S$. typhi phages (1-9), lanes negative K.pneumonia phages (10-16), positive lanes of E.coli phages (17-21). Lane M: DNA ladder (100bp).

\section{C: negative control.}

\section{Discussion}

Increase of multidrug-resistant bacteria and other losses, supporting alternative therapy development. Phage therapy may be seen as an effective method for the prevention and control of bacterial infection [11]. The current study, the lytic and specific phages to the bacterial strains were isolated from different environmental sources; sewage was the main source; this finding is consistent with other studies ${ }^{[12]}$.

The phages are the most abundant organisms in water, feces, soil and sewage water, therefore they are considered good indicators of bacteria presence ${ }^{[13]}$. 
RAPD-based method do not require sequence information when designing the PCR primers. We are therefore highly dependent on laboratory conditions such as DNA template concentration, PCR and electrophoretic environments, were selected to test several experimental conditions in order to produce reproducible RAPD patterns and gain a preliminary insight into the power of this approach to discrimination ${ }^{[14]}$.

As shown in Fig. 4 OPL5, RAPD5 primer produced distinct amplicon band patterns . in current study Fig.4a shown S.typhi phages were different among them Whereas, K.pneumonia phages were similar these results are disagree with the researchers' findings [15]. The results shown in Fig.4b showed S.typhi phages (1-6) were similar after use RAPD5 primer in the RAPD-PCR technique . The phages of S.typhi $(7,5,3)$ was similar too. S.typhi phages 4,8 differed from the other phages, The results of the current study are consistent with the findings ${ }^{[16]}$.

Fig.5a, Restriction endonuclease (NdeI, SspI) showed the enzyme's effectiveness in digesting the phage DNA fragments, SspI was more efficient and producing DNA bands. Enzymes can digest DNA at Recognition site or more than in the same strand. NdeI was digested of DNA in the same site and bands of the same molecular weight appeared for S.typhi phages lanes(1-9) and E.coli phages lanes (17-21), which means that the phages are similar. But K.pneumonia phages(10-16) was negative results with using NdeI enzyme, these results disagree with results ${ }^{[17]}$.

In Fig.5b Endonuclease SspI digesting the DNA phages of S.typhi(1-9) and E.coli phages(17-21) and produces different bands pattern,which means that the phages are different among them. These results are consistent with ${ }^{[18]}$. K.pneumonia phages(10-16) was negative results after digesting with SspI enzyme.

\section{Conclusions}

Phages characterization has shown that it has been very successful in lysing E.coli, K.pneumonia, S.typhi, it can be a good candidate for use as an alternative nontoxic green sanitizer. Host range research, however, revealed that phages did not infect other clinical strains of E.coli, K.pneumonia, S.typhi included in this review, indicating that more virulent bacteriophages unique to various bacterial strains will be screened and collected in the future. In potential phage applications a pool of lytic phages may be more effective against E.coli, K.pneumonia, S.typhi strains.

Acknowledgements: We would like to thank the Department of Biology, College of Science, Anbar University, Iraq and Anbar Health office for their technical assistance. We thank Assit. Prof. Ahmed Abdul Jabbar Suleiman, Biotechnology Department, College of Science, University of Anbar, for his help in this study.

\section{Conflict of Interest: None}

\section{Funding: Self}

Ethical Clearance: Not required

\section{References}

1. LaVergne S, Hamilton T, Biswas B, Kumaraswamy M, Schooley RT, Wooten D. Phage therapy for a multidrug-resistant Acinetobacter baumannii craniectomy site infection. In: Open forum infectious diseases. Oxford University Press US; 2018. p. ofy064.

2. Zaman S Bin, Hussain MA, Nye R, Mehta V, Mamun KT, Hossain N. A review on antibiotic resistance: alarm bells are ringing. Cureus. 2017;9(6).

3. Clokie MR, Millard AD, Letarov A V, Heaphy S. Phages in nature. Bacteriophage 1: 31-45. 2011.

4. Stalin N, Srinivasan P. Efficacy of potential phage cocktails against Vibrio harveyi and closely related Vibrio species isolated from shrimp aquaculture environment in the south east coast of India. Vet Microbiol. 2017;207:83-96.

5. Lanzone V, Tofalo R, Fasoli G, Perpetuini G, Suzzi G, Sergi M, et al. Food borne bacterial models for detection of benzo [a] pyrene-DNA adducts formation using RAPD-PCR. Microb Biotechnol. 2016;9(3):400-7.

6. Preethirani PL, Isloor $\mathrm{S}$, Sundareshan $\mathrm{S}$, Nuthanalakshmi V, Deepthikiran K, Sinha AY, et al. Isolation, biochemical and molecular identification, and in-vitro antimicrobial resistance patterns of bacteria isolated from bubaline subclinical mastitis in South India. PLoS One. 2015;10(11):e0142717.

7. Amiri Fahliyani S, Beheshti-Maal K, Ghandehari F. Novel lytic bacteriophages of Klebsiella oxytoca ABG-IAUF-1 as the potential agents for mastitis phage therapy. FEMS Microbiol Lett. 2018;365(20):fny223.

8. Ghasemi SM, Bouzari M, Emtiazi G. Preliminary characterization of Lactococcus garvieae 
bacteriophage isolated from wastewater as a potential agent for biological control oflactococcosis in aquaculture. Aquac Int. 2014;22(4):1469-80.

9. Garcia P, Ladero V, Suarez JE. Analysis of the morphogenetic cluster and genome of the temperate Lactobacillus casei bacteriophage A2. Arch Virol. 2003;148(6):1051-70.

10. Johansson P-O. Evaluating health risks. Cambridge Books. 1995;

11. Maal KB, Delfan AS, Salmanizadeh S. Isolation identification of Klebsiella pneumonia and Klebsiella oxytoca bacteriophages and their applications in waste water treatment and coliform's phage therapy. Res J Env Sci. 2014;8(3):123-33.

12. Junn HJ, Youn J, Suh KH, Lee SS. Cloning and expression of Klebsiella phage K11 lysozyme gene. Protein Expr Purif. 2005;42(1):78-84.

13. Aprea G, D'Angelo AR, Prencipe VA, Migliorati G. Bacteriophage morphological characterization by using transmission electron microscopy. J Life Sci. 2015;9(1):214-20.
14. Gutiérrez D, Martín-Platero AM, Rodríguez A, Martínez-Bueno M, García P, Martínez B. Typing of bacteriophages by randomly amplified polymorphic DNA (RAPD)-PCR to assess genetic diversity. FEMS Microbiol Lett. 2011;322(1):907.

15. Comeau AM, Short S, Suttle CA. The use of degenerate-primed random amplification of polymorphic DNA (DP-RAPD) for strain-typing and inferring the genetic similarity among closely related viruses. J Virol Method. 2004;118(2):95100.

16. Cucic S. Development of a prototype rapid method for the detection of Escherichia coli and Salmonella enterica subspecies enterica serovar Newport based on phage amplification and detection of progeny phage by Loop Mediated Isothermal Amplification. 2017.

17. Kumari S, Harjai K, Chhibber S. Isolation and characterization of Klebsiella pneumoniae specific bacteriophages from sewage samples. Folia Microbiol (Praha). 2010;55(3):221-7. 